\section{EMBRYRIDDLE \\ Aeronautical University}

SCHOLARLY COMMONS

\section{International Journal of Aviation,} Aeronautics, and Aerospace

\title{
A Model for Inhalation of Infectious Aerosol Contaminants in an Aircraft Passenger Cabin
}

\author{
Bert A. Silich \\ Vector Vantage LLC, BSilich@VectorVantage.com
}

Follow this and additional works at: https://commons.erau.edu/ijaaa

Part of the Aerodynamics and Fluid Mechanics Commons, Biostatistics Commons, Disease Modeling Commons, Environmental Public Health Commons, Infectious Disease Commons, Respiratory Tract Diseases Commons, and the Virus Diseases Commons

\section{Scholarly Commons Citation}

Silich, B. A. (2021). A Model for Inhalation of Infectious Aerosol Contaminants in an Aircraft Passenger Cabin. International Journal of Aviation, Aeronautics, and Aerospace, 8(1). https://doi.org/10.15394/ ijaaa.2021.1545

This Article is brought to you for free and open access by the Journals at Scholarly Commons. It has been accepted for inclusion in International Journal of Aviation, Aeronautics, and Aerospace by an authorized administrator of Scholarly Commons. For more information, please contact commons@erau.edu. 
This article introduces a mathematical model of how contaminated aerosolized particles can behave an enclosed spaces such as an aircraft passenger cabin. Since it is impractical to experimentally measure all the various cabin environments under different conditions directly, incorporating a model can enhance the understanding of how key variables play a role in aerosol contamination within a closed space. Having a method to determine the concentration and time to inhale an infectious number of aerosolized virus particles during different phases of flight, with or without system malfunctions, may contribute to science providing the aviation industry the insight they need to develop safer flight guidelines for aircrew and passengers. There is a notable advantage in developing a model, as scientific knowledge of aerosol contamination increases, models can easily be adjusted to incorporate additional variables or parameters

Common modes of transmission of an infectious disease include spreading by droplets and aerosols. This paper is only concerned with contaminants that travel by way of aerosolized particles. Different infectious agents use varying combinations of modes of transmission. Nothing in this paper is intended to supersede or minimize what is known about a specific agent and other modes of transmission. The COVID-19 pandemic is mentioned as a timely example to consider in this paper. The reader should realize that the current understanding of COVID-19 transmission of infection is not adequate enough to determine if the risk or probability of obtaining a COVID-19 infection by aerosol transmission can be soley based on the results of this model.

\section{Background}

A method is proposed to estimate the recommended flight time for passengers and aircrew under normal operations and emergency conditions when a human respiratory, infectious, aerosol contaminant is present in an aircraft passenger cabin. First, the process of determining how to statistically estimate the number of contagious passengers on board an aircraft is described. Then, recommended flight time limits are obtained by assuming the number of inhaled infectious particles are a measure of the chance of obtaining an infection. Before relying on this model, the user needs to determine if the number of inhaled particles is related to the transmission of infection for their particular contaminant. Experimentation is also required to verify the validity of this model. Results are calculated for various ground and flight scenarios including malfunctions of the aircraft air conditioning and pressurization systems. The example will show how this type of information can lead to information that can assist a pilot in making sound decisions when an aircraft air conditioning or pressurization system malfunction occurs in the setting of an aerosolized contaminant.

The model uses air flow analysis of a closed container to determine the level of aerosol contamination in the cabin and the number of infectious particles inhaled 
by the passengers. The results presented here are based on the mathematical solution of this model. This solution assumes certain ideal conditions such as there is perfect mixing of the contaminants in the air and the aerosol particle size does not affect the results. Ideal conditions are often not met in physical situations, models can still be of value in detecting what the important factors are in a specific scenario. Discrepancies between a model's results and laboratory measured results often exist. Accounting for any discrepancies in the model should be part of future work. Since some discrepancies may remain unknown the use of safety factors can be incorporated to avoid underestimating the desired limits. This article will illustrate in the example how safety factors can be applied.

Controlling both the droplet component and the aerosol component of an infectious process is critical to stopping the spread of an infection. The transmission of droplets between people can generally be reduced by barriers such as masks, gloves, face shields, goggles, gowns and wall partitions. Reducing the inhalation of aerosol contaminants by healthy individuals within a closed space requires a constant flow of uncontaminated air replacing the contaminated air. The results of this ideal model show two key concepts. First, the magnitude of the uncontaminated air flow, Q $\left(\mathrm{m}^{\wedge} 3 / \mathrm{hr}\right)$, determines the steady state level of the contaminant concentration. Second, the air changes per hour $(\mathrm{ACH})$ determines the rate at which the contamination will approach the steady state level.

In medicine, there is a term commonly used called the ID $_{50}$ (infective dose 50 ). It is the number of infectious particles a host is exposed to over a specified time period that would infect $50 \%$ of the population. In a similar manner other values such as ID $_{75}$ or ID 95 can be determined. It is not in the scope of this article to specify the value of infective dose to be used by the user in this model. The correct value should be obtained based on the properties of the specific infectious agent of interest. The value selected for the model is referred to as the infectious dose limit (IDL). For simplicity, the time to inhale the IDL will be assumed to be the same as the time periods discussed in the examples. Similar concepts of an infectious dose and viral load have been used to analyze the 1918 influenza pandemic (Paulo et al., 2010). In the case of a viral infection these particles could be referred to as virions. Realize, the infective dose can be difficult to determine which is a weakness of this model's approach. As a matter of current interest, it is not specifically known for COVID-19 according to Schröder (2020).

The example aircraft used for this analysis is a Boeing 767-300. This aircraft was chosen to parallel one of the aircraft in a report sent to United States Transportation Command (USTRANSCOM) and the United States Air Force (USAF) Air Mobility Command (AMC) by Silcott et al. (2020). The model developed for the process described here is not restricted to this aircraft and it can be applied to any aircraft cabin. The basis of this model was adapted from a similar 
model by Silich (2020) applied to a hospital environment to assist in keeping healthcare workers safe from aerosol contaminants.

\section{Analysis}

The first part of this analysis requires estimating the number of passengers on board that are expected to be infectious. Two possible approaches are demonstrated. The first approach assumes there is an opportunity to perform laboratory tests on passengers prior to the flight and the second approach relies on clinical screening questions prior to flight. Assume we are testing $\mathrm{n}$ equal to 100 passengers for an infectious disease with prevalence in the population (Pp\%) of $5 \%$. Also, assume this specific test has a false positive percentage value $(\mathrm{Fp} \%)$ of $5 \%$ and a false negative percentage value (Fn\%) of 30\%. Using the method detailed in Appendix 1, it can be estimated 8 passengers will be removed from the flight, 5 who had false positive results and 3 who had true positive results. Of the 92 passengers that are allowed to board the flight, 2 will have the infectious disease. This is summarized in Table 1.

Table 1 - Passenger profile with testing

Total passengers before testing - 100

Disease prevalence - $5 \%$

Testing False positives - 5\%

Testing False negatives - $\mathbf{3 0 \%}$

\begin{tabular}{rcc} 
Passengers & $\begin{array}{c}\text { Removed } \\
\text { from Flight }\end{array}$ & $\begin{array}{c}\text { Remain } \\
\text { on Flight }\end{array}$ \\
\hline Infected & 3 & 2 \\
Not Infected & 5 & 90 \\
\hline Total & 8 & 92
\end{tabular}

The second approach involves doing medical screening without laboratory testing. Again, assume $\mathrm{n}=100$ and $\mathrm{Pp} \%=5 \%$. Let the screening process have a $\mathrm{Fp} \%=3 \%$ and a Fn $\%=80 \%$. Using the method described in Appendix 1, Table 2 shows that 4 passengers will be removed from the flight, 3 with false positive results and 1 with a true positive result. Of the 96 passengers allowed to board the flight, 4 will have the infectious disease. 
Table 2 - Passenger profile with clinical screening

Total passengers before testing - 100

Disease prevalence - $5 \%$

Clinical False positives - $3 \%$

Clinical False negatives - $80 \%$

\begin{tabular}{rcc} 
Passengers & $\begin{array}{c}\text { Removed } \\
\text { from Flight }\end{array}$ & $\begin{array}{c}\text { Remain } \\
\text { on Flight }\end{array}$ \\
\hline $\begin{array}{r}\text { Infected } \\
\text { Not Infected }\end{array}$ & 1 & 4 \\
\hline Total & 4 & 92 \\
\hline
\end{tabular}

The second part of the analysis uses a model for aerosol contaminants within a closed container. It is assumed that the main sources of aerosol contamination is from sick passengers and from recycled intake airflow. If experimentation shows other sources caused by droplet dispertion and evaporation from passenger movement or clothing are significant, these terms can be included in the equation. Appendix 2 shows the concentration of an aerosol contaminant in the aircraft cabin, $\left[\mathrm{C}(\mathrm{t})_{\mathrm{V} \text { ref }}\right]$, is

$$
\left[\mathrm{C}(\mathrm{t})_{\mathrm{V} \text { ref }}\right]=\left(\frac{\alpha}{\beta * \mathrm{Q}_{\text {out }}}\right)+\left\{\left[\mathrm{C}(0)_{\mathrm{V} \mathrm{ref}}\right]-\left(\frac{\alpha}{\beta * \mathrm{Q}_{\text {out }}}\right)\right\} * \mathrm{e}^{-\beta * \mathrm{ACH} * \mathrm{t}}
$$

Where

$$
\begin{aligned}
& \alpha=\mathrm{n} * \mathrm{q}_{\text {breath }} *\left[\mathrm{C}_{\text {breath }}\right]+\dot{\mathrm{P}}_{\text {in }} \\
& \beta=(1-\mathrm{k}(1-\mathrm{HEPA})) \neq 0 \\
& \mathrm{k}=\frac{\mathrm{Q}_{\text {in }}}{\mathrm{Q}_{\text {out }}} \\
& \text { HEPA }=\frac{\text { HEPA\% }}{100}
\end{aligned}
$$

Alpha represents external sources of contamination. The flow rate and concentration refer to an infected source's breath where all infected individuals are considered equal. $\dot{\mathrm{P}}_{\text {in }}$ refers to any other constant sources determined to be significant. Beta represents the HEPA filtered air that is recycled back into the cabin where $\mathrm{k}$ is the proportion of $\mathrm{Q}_{\text {out }}$ that is recycled back as $\mathrm{Q}_{\text {in }}$. 


\section{Definitions}

$\mathrm{ACH}$ - Air Changes / hour

$[C]-$ Concentration (particles $/ \mathrm{m}^{\wedge} 3$ )

$\mathrm{n}$ - number of identical contaminant sources

$\mathrm{P}$ - \# Contaminant particles

$\mathrm{Q}, \mathrm{q}$ - Flow rate $\left(\mathrm{m}^{\wedge} 3 /\right.$ hour $)$

RR - Respiratory rate (1/hour)

$\mathrm{t}$ - time (hours)

TV - Tidal volume $\left(\mathrm{m}^{\wedge} 3\right)$

$\mathrm{V}_{\text {ref }}-$ Reference cabin volume $\left(\mathrm{m}^{\wedge} 3\right)$

\section{Important Relationships}

$[\mathrm{C}]=\frac{\mathrm{P}}{\mathrm{V}} \quad\left(\right.$ particles $\left./ \mathrm{m}^{\wedge} 3\right)$

$\left[\mathrm{C}_{\text {out }}\right]=\left[\mathrm{C}_{\mathrm{V} \text { ref }}\right]$

$\mathrm{q}_{\text {breath }}=(\mathrm{TV} * \mathrm{RR})$

$\mathrm{Q}_{\text {out }}=\mathrm{ACH} * \mathrm{~V}_{\text {ref }}$

Flow rate of contaminant

$\frac{\mathrm{dP}}{\mathrm{dt}}=\dot{\mathrm{P}}=\mathrm{Q} *[\mathrm{C}] \quad$ (particles/hour)

Remember that this solution requires perfect mixing of the aerosolized contaminant particles occurs throughout the cabin volume and all aerosol particle sizes are affected equally by the air flow. Equation (1) shows there is exponential decay towards a steady state value of $\left(\frac{\alpha}{\beta * Q_{\text {out }}}\right)$. The time for $x y \%$ of decay towards the steady state value is shown in Appendix 2.

$$
\mathrm{T}_{\mathrm{xy} \%}=-\frac{\ln (1-0 . \mathrm{xy})}{\beta * \mathrm{ACH}}
$$

For example, the time for $75 \%$ of the decay towards the steady state value would be

$$
\mathrm{T}_{75 \%}=-\frac{\ln (1-0.75)}{\beta * \mathrm{ACH}}=\frac{1.39}{\beta * \mathrm{ACH}} \text { (hours) }
$$

Vital signs are summarized in Table 3. Normal vital signs of a healthy patient include a tidal volume (TV) of approximately $0.7 \mathrm{ml} / \mathrm{kg}$ and a respiratory rate (RR) of about 15 breaths per minute. We use this information to calculate a healthy individual's $\mathrm{q}_{\text {breath }}=(\mathrm{TV} * \mathrm{RR})$. In this analysis, the tidal volume will be 
assumed to be a constant $0.5 \mathrm{~L}$. For ground and flight profiles \#1 thru \#4, the respiratory rate will be assumed to be slightly elevated at a constant 20 breaths per minute because of apprehension of flying during a pandemic and the requirement to wear a mask. Here is one example of how to incorporate a safety factor into the model. It is important to avoid underestimating the healthy passenger's respiratory rate, otherwise you may not detect a condition where the IDL was exceeded. As previously stated infective doses can be difficult to determine. For the purpose of this articles example the IDL of a fictitious disease will be selected to be equal to 1,000 infectious aerosol particles. An infectious passenger is assumed to have the same $\mathrm{TV}=0.5 \mathrm{~L}$ but will have an increased respiratory rate of 40 breaths per minute. This respiratory rate is higher then a typical septic patient and is not physiologically sustainable, it is important not to underestimate the output from a source. The purpose here is to demonstrate another method of adding a safety factor. By doubling the respiratory rate compared to healthy individuals we have in effect doubled the number of sick passengers on board. It is the intention of this article to demonstrate how safety factors can be applied in a model and not to recommend specific magnitudes for the safety factor. That should be determined by testing designed for that purpose and by the confidence level of the properties of the particular infectious agent.

The model used for this analysis assumes a worst case scenario where the infectious passengers are not wearing a mask so their exhalations are not filtered. This is a prudent assumption because it can be difficult to get a person who is short of breath to feel comfortable when wearing a mask. This is another example of incorporating a safety factor. The sum total of the concentration of infectious aerosol particles in an infected passenger's exhalations released into the cabin environment will assumed to be a constant 8.89 particles/L and can be calculated from the data in Silcott et al. (2020). Realize this concentration value can vary based environmental factors such as the density altitude and humidity and is selected for example purposes only.

Table 3 - Passenger criteria and vital signs

\begin{tabular}{|c|c|c|c|c|c|}
\hline Title - abbreviation - & $\begin{array}{c}\text { Healthy } \\
\text { Person }\end{array}$ & $\begin{array}{c}\text { Article } \\
\text { Healthy } \\
\text { Passenger }\end{array}$ & $\begin{array}{c}\text { Article } \\
\text { Infectious } \\
\text { Passenger }\end{array}$ & $\begin{array}{c}\text { USTRANSCOM } \\
\text { Report }\end{array}$ & (units) \\
\hline Infectous Exhaled Concentration - & & & 8.89 & 8.89 & (particles/L) \\
\hline Number Sick Pax on board - $n-$ & & & 4 & 1 & \\
\hline Respiratory Rate - RR - & 15 & 20 & 40 & 15 & $(1 / \mathrm{min})$ \\
\hline Tidal Volume - TV - & 0.5 & 0.5 & 0.5 & 0.5 & (L) \\
\hline Infectious Dose Limit - IDL - & 1,000 & 1,000 & & 1,000 & (particles) \\
\hline
\end{tabular}

Note. USTRANSCOM data provided by Silcott et al. (2020). 
To determine if the IDL is reached, the number of inhaled aerosol particles by a healthy individual, $\mathrm{P}_{\mathrm{inh}}$, is given by an equation derived in Appendix 2 .

$$
\mathrm{P}_{\text {inh }}=\left.\mathrm{q}_{\text {inh }} *\left(\left(\frac{\alpha}{\beta * \mathrm{Q}_{\text {out }}}\right) * t+\frac{\left\{\left[\mathrm{C}(0)_{\mathrm{V} \mathrm{ref}}\right]-\left(\frac{\alpha}{\beta * \mathrm{Q}_{\text {out }}}\right)\right\}}{-\beta * \mathrm{ACH}} * \mathrm{e}^{-\beta * \mathrm{ACH} * \mathrm{t}}\right)\right|_{\mathrm{t} 1} ^{\mathrm{t} 2}
$$

with $n=1$ in $\alpha$ from equation (2).

Except for the time variable, t, the terms in equations (1) thru (8) are

constants. $\dot{\mathrm{P}}_{\text {in }}$ (particle/hour) is contained in $\alpha$ and could represent any external source of contaminant particles that supply a constant input. If the source for $\dot{\mathrm{P}}_{\text {in }}$ is not constant these equations can still be used by applying a numerical methods approach. The fact that passengers are inhaling particles and therefore removing particles from the cabin would have the effect to reduce the concentration of the aircraft cabin. This affect is will be considered negligible for the example discussed. The calculations required for this model and analysis in the discussion are all accomplished using an Excel spread sheet program.

\section{Discussion}

We now have a model which estimates when the IDL will be exceeded by a group of passengers on a flight incorporating aircraft malfunctions of the air conditioning and pressurization system. Using information about the disease profile and testing capability it can be estimated how many infectious passengers may be on board. For the remainder of this discussion, it will be assumed there are 4 infected passengers on board as in Table 2. The vital signs from Table 3 are used for the flight profiles in segments \#1 thru \#4. The healthy passengers have a $R R=$ 20 breaths $/$ minute and TV $=0.5 \mathrm{~L}$. Their IDL will be 1,000 particles inhaled. Infectious passenger's $\mathrm{RR}=40$ breaths/minute, $\mathrm{TV}=0.5 \mathrm{~L}$ and they will create 8.89 infectious particles/L of exhaled breath.

The first flight profile consists of four segments shown in Table 4. Segment \#1 is a normal ground operation that starts with the passengers cleared for flight on board and lasts 1 hour. The cabin ACH during ground operations is assumed to be lower than during flight operations and equals 10 . The cabin volume of $264 \mathrm{~m}^{\wedge} 3$ is similar to that of a Boeing 767. 50\% of the air is recycled from the cabin after being filtered by a HEPA $99.97 \%$ filter. The passenger's masks are assumed to be for droplets only and have no effect of filtering an aerosolized particle. The initial cabin concentration was 0.0 particles $/ \mathrm{m}^{\wedge} 3,1$ hour later the cabin concentration would reach 16.2 particles $/ \mathrm{m}^{\wedge} 3$ and each healthy passenger would have inhaled 9 particles. If conditions remained constant at the 1-hour point, the passengers would have 102 hours before inhaling the IDL. Figure 1 shows details of the cabin concentration and inhaled infectious dose as a function of time. 


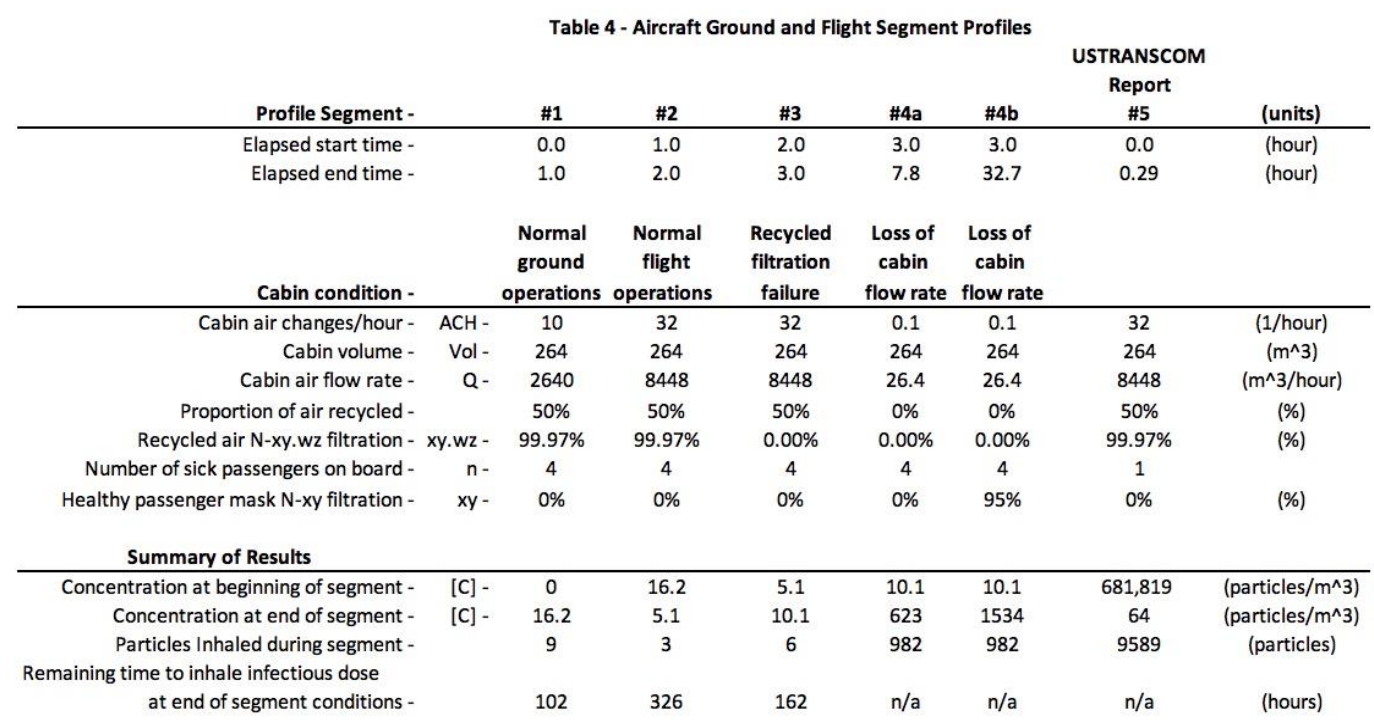

Note. USTRANSCOM data provided by Silcott et al. (2020).

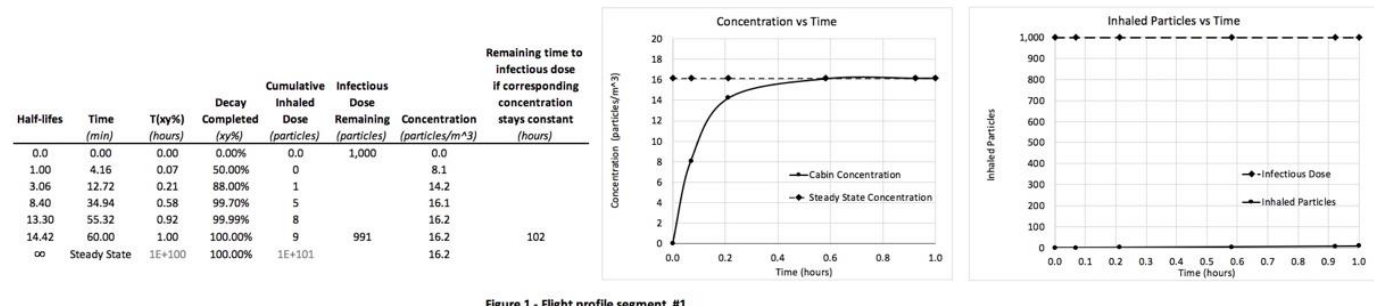

Segment \#2 starts at take-off and consists of 1 hour of normal flight operations. The $\mathrm{ACH}$ has increased to 32 for this segment. The initial cabin concentration is 16.2 particles $/ \mathrm{m}^{\wedge} 3$ and the final concentration would be 5.1 particles $/ \mathrm{m}^{\wedge} 3$. Passengers would have inhaled 3 particles during this hour for a total of 12 for the flight so for. They are well below the IDL of 1,000 particles. If the conditions at 2 hours remained constant the passengers would reach the IDL in 326 additional hours. Figure 2 shows details of the cabin concentration and inhaled infectious dose as a function of time. 

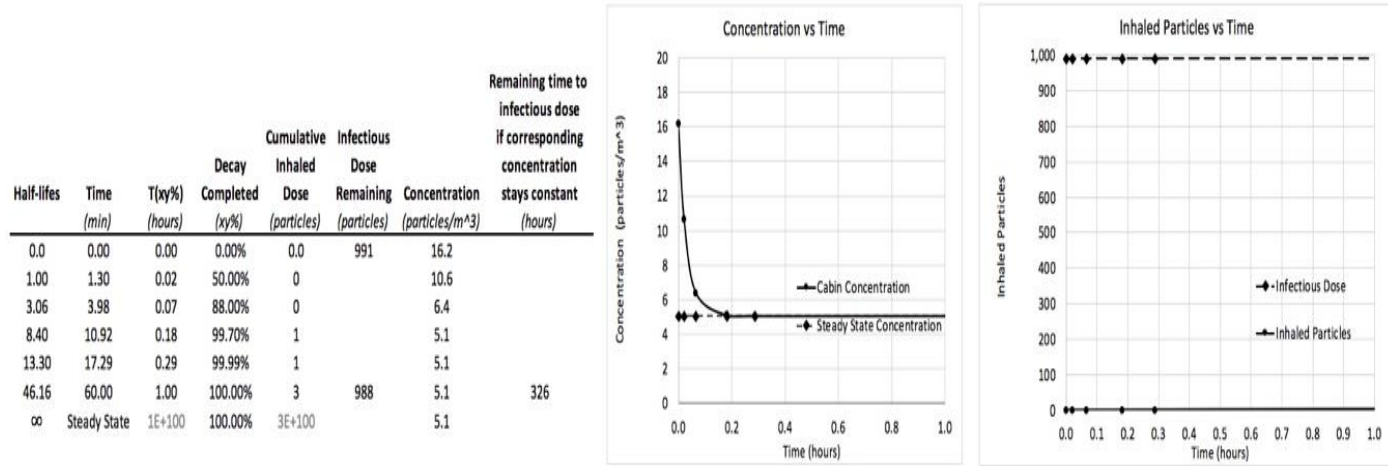

Figure 2- Flight profile segment \#2

Segment 3 starts at the 2-hour point and lasts 1 hour. During this segment, the recycling filter fails, and the $50 \%$ recycled air is no longer filtered. The initial cabin concentration is 5.1 particles $/ \mathrm{m}^{\wedge} 3$ and the final concentration would increase to 10.1 particles $/ \mathrm{m}^{\wedge} 3$. Passengers would have inhaled 6 particles during this hour for a total of 18 for the flight so for. Still well below the IDL of 1,000 particles. If the conditions at 3 hours remained constant the passengers would reach the IDL in 162 additional hours. Figure 3 shows details of the cabin concentration and inhaled infectious dose as a function of time. Notice that failure of the HEPA filter affects the beta value and leads to a doubling of the steady state concentration in this scenario. Fortunately, cabin air filtration is not the only means by which the cabin contaminants are cleared. Equation (1) shows the cabin contaminant concentration is also dependent on $Q_{\text {out }}$. The purpose of recycling HEPA filtered air is to conserve engine power by supplementing the bleed air from the engines which are typically the main source of clean replacement input air.
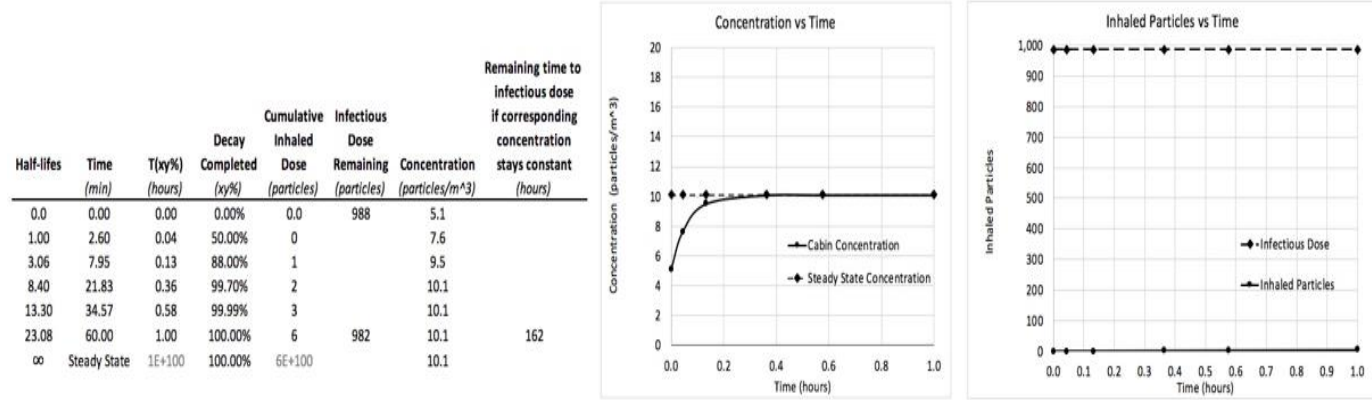

Figure 3. Flight profile segment \#3

Segment \#4a starts at the 3-hour point and lasts until the IDL is reached in 4.8 hours. During this segment, there is a near complete loss of cabin airflow, $Q_{\text {out }}$, from $8,448 \mathrm{~m}^{\wedge} 3 /$ hour to $26.4 \mathrm{~m}^{\wedge} 3 /$ hour with an $\mathrm{ACH}=0.1$. There is also no recycling of air in the cabin. The initial cabin concentration is 10.1 particles $/ \mathrm{m}^{\wedge} 3$ 
and in 4.8 hours the final concentration would increase to 623 particles $/ \mathrm{m}^{\wedge} 3$. Passengers would have inhaled 982 particles during the 4.8 hours putting them at the IDL at this time. Figure $4 a$ shows details of the cabin concentration and inhaled infectious dose as a function of time. Therefore, the aircrew would want to land prior to the elapsed time of 7.8 hours.
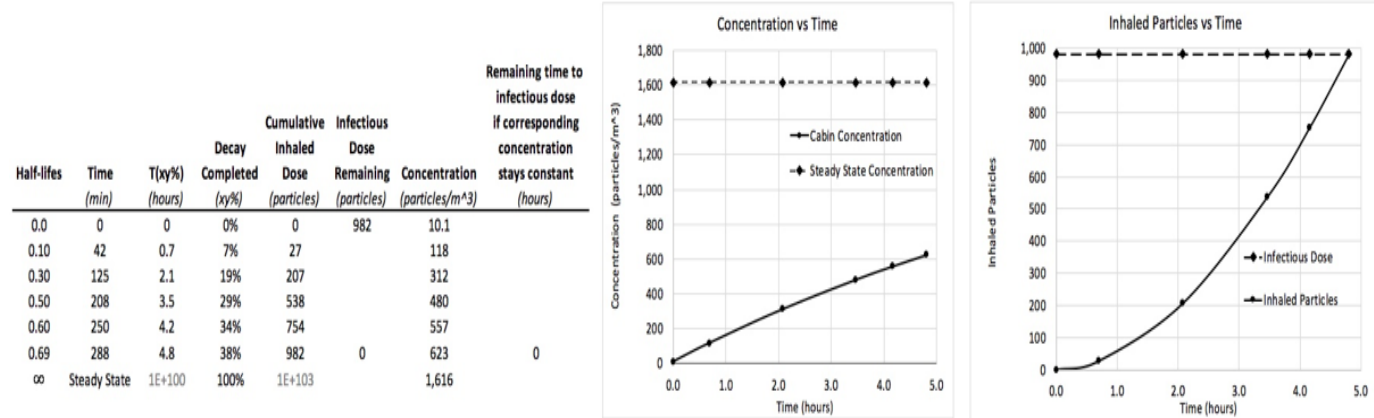

Figure 4a - Flight profile segment $\# 4$

Segment \#4b is the same profile as segment \#4a except at the time there is the loss of cabin airflow the passengers were provided N-95 masks to wear. Segment \#4b starts at the 3-hour point and lasts until the IDL limit is reached in 29.7 hours. The initial cabin concentration is again 9.8 particles $/ \mathrm{m}^{\wedge} 3$ and in 29.7 hours the final concentration would increase to 1534 particles $/ \mathrm{m}^{\wedge} 3$. Because they are wearing N-95 masks, passengers would have inhaled 982 particles during the 29.7 hours putting them at the IDL at this time. Figure $4 \mathrm{~b}$ shows details of the cabin concentration and inhaled infectious dose as a function of time. Therefore, the aircrew would want to land prior to the elapsed time of 32.7 hours. Having N-95 masks available for passengers increased the elapsed time from 7.8 hours to 32.7 hours in segment \#4a and \#4b respectively.
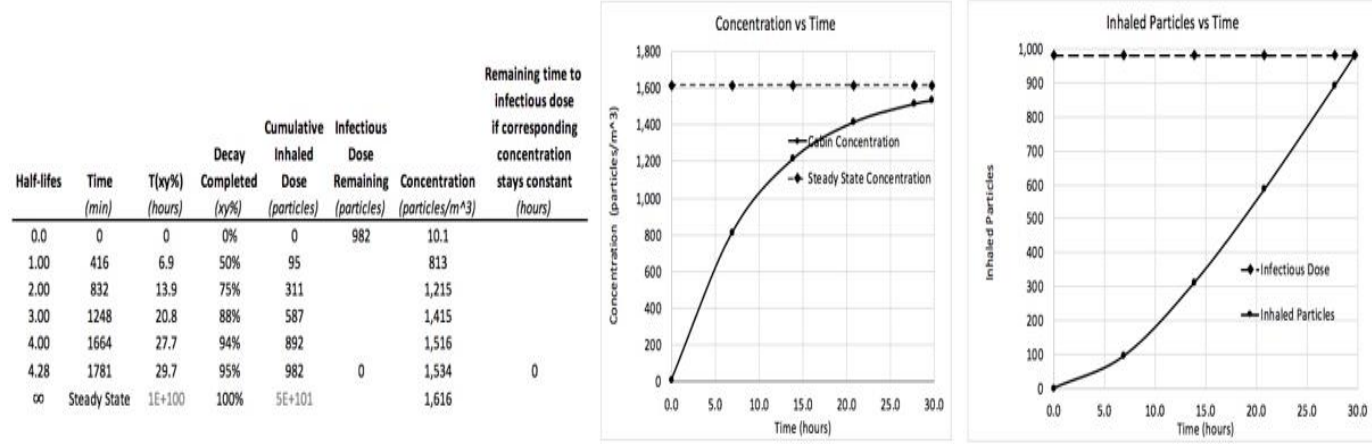

Figure 4b - Flight profile segment \#4b 
Pilots would not require this level of detail. From this model, tables could be generated to benefit a pilot's decision-making capability. One example is Table 5. Prior to take-off, pilots would be provided the range of expected infectious passengers on their flight based on preflight testing or screening performed. Table 5 provides a worst-case flight time to get to a take-off alternate airfield and remain below the IDL when the air conditioning and pressurization system failure occurrs immediately after take-off. For example, if there were 6-10 probable infected passengers on board, the aircraft would need to land within 3.0 hours of taking off. If that is not possible, they could extend their flight time to 16.1 hours if N-95 masks were distributed and worn by all of the healthy passengers.

Table 5 - Time for passengers to reach infectious dose limit (IDL)

With complete air conditioning and pressurization

failure immediately after take-off

\begin{tabular}{|c|c|c|c|}
\hline $\begin{array}{l}\text { Number of } \\
\text { Infectious } \\
\text { Passengers } \\
\text { On Board } \\
\text { (n) }\end{array}$ & $\begin{array}{l}\text { Without N-95 Masks } \\
\text { (hours)* }^{*}\end{array}$ & $\begin{array}{c}\text { With N-95 Masks } \\
\text { (hours)* }\end{array}$ & $\begin{array}{l}\text { Normal } \\
\text { Flight } \\
\text { Operations } \\
\text { (hours)* }^{*}\end{array}$ \\
\hline $0-5$ & 4.3 & 25.5 & 261 \\
\hline $6-10$ & 3.0 & 16.1 & 129 \\
\hline $11-15$ & 2.4 & 12.4 & 85 \\
\hline
\end{tabular}

Silcott et al. (2020) includes ground and flight testing of a Boeing 767 for USTRANSCOM and AMC. The parameters of one of these tests were included in Table 3 and Table 4 (segment \#5). In this test, the aircraft was filled with $1.8 \times 10^{\wedge} 8$ simulated infectious particles to a concentration of 681,819 particles $/ \mathrm{m}^{\wedge} 3$. Then at an $\mathrm{ACH}=32$ and using particle counting sensors in the aircraft that study concluded that in approximately 6 minutes $99.9 \%$ of the contaminants were removed.

This model was not designed to simulate all of the conditions of the USTRANSCOM/AMC report but using the same parameters certain conclusions could be made. The model showed if a passenger was in the aircraft cabin at the start of the test, they would reach the IDL $=1,000$ inhaled particles in 0.21 minutes. If a passenger entered the cabin at the 6-minute point, $95.93 \%$ of the decay towards steady state conditions would have occurred and the passengers would reach the IDL in 21.4 hours. If a passenger entered the cabin at the 13.0-minute point, $99.90 \%$ of the decay towards steady state conditions would have occurred and the passengers would reach the IDL in 34.5 hours. Finally, if a passenger entered the 
cabin at the 17.4-minute point, $99.99 \%$ of the decay towards steady state conditions would have occurred and the passengers would reach the IDL in 34.7 hours. Each of these results assume that after the 17.4-minute point the cabin concentration remains steady at the $99.99 \%$ level of 64 particles $/ \mathrm{m}^{\wedge} 3$. Figure 5 shows details of the cabin concentration and inhaled infectious dose as a function of time.
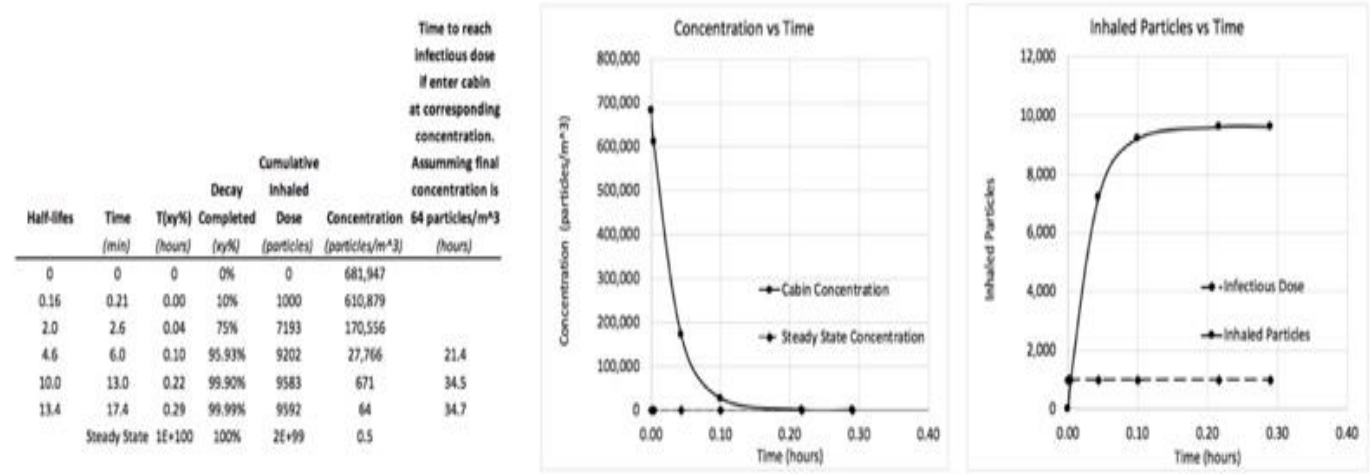

Figure S- Flight Proflie Segment as

The USTRANSCOM/AMC report concluded that in approximately 6 minutes $99.9 \%$ of the contaminants were removed instead of the model's result of 13.0 minutes. The model calculated that only $95.93 \%$ of the contaminants would be removed at 6 minutes. Reasons for these differences could be due to the set-up of the model not matching the physical conditions of the USTRANSCOM/AMC report. Another reason could be the model's ideal requirement for perfect mixing of all aerosol particles of all sizes may not be occurring throughout the entire cabin. Perfect mixing in an actual aircraft is unlikely when concentration levels can vary based on where the infectious passengers sit and the location of the cabin air inflow and outflow valves. Without complete mixing of the air, the $\mathrm{ACH}$ would effectively be higher leading to the reduced decay to steady state time seen in the USTRANSCOM/AMC report. The trends of each approach are similar and an advantage of incorporating a model into this problem is it can be applied to any aircraft in multiple ground and flight conditions. It would be time consuming and expensive to directly test all aircraft cabins in several different ground and flight conditions.

\section{Summary}

Using a model in conjunction with experimental results to calculate the aircraft cabin contamination concentration of aerosols and the number of contaminant particles inhaled by healthy passengers can enhance our knowledge of how aerosol contaminants may affect the occupants of an aircraft passenger cabin. A model can allow for safety factors during the various phases of operation where precise knowledge may be lacking. Additional ground and flight tests should be 
performed to better determine what the magnitude of a safety factor should be. This model can estimate the cabin concentration of an aerosol during all phases of operation, with and without air conditioning and pressurization system malfunctions for any type of aircraft. It will also estimate the time it will take to inhale the selected IDL. Using all of the tools discussed here along with experimentation to obtain the best estimate possible for a recommended flight time may benefit aviation safety with respect to an aerosol contaminant. For the sake of simplicity, ground operations after landing have not been considered in these scenarios. The flight attendants in the cabin would be considered part of the passenger group for these calculations. If the cockpit does not have a separate air conditioning and pressurization system, the cockpit crew would also be part of the passenger group.

Two segments (\#1 - \#2) of ground and flight operations were discussed with normal operations. Segments \#3, \#4a and \#4b included aircraft air conditioning and pressurization system failures including adding passenger N-95 masks. In each of these cases the beginning and ending contaminant concentrations were calculated as well as the number of inhaled aerosol contaminant particles. The time to reach the IDL was also determined.

Pilots would not require all of these details about aerosol contamination. A table with recommended flight times remaining for various malfunctions and conditions was presented. Having this information could help pilots make more informed decisions when choosing appropriate alternate landing fields during inflight emergencies or route changes due to weather for example. Other tables could be developed to cover different scenarios. Dispatch could also be contacted if an unusual scenario occurs and use this model's computer program to calculate additional options for the aircraft's specific situation.

This analysis only considers the aerosol component of infections only. Nothing in these results supersede or removes the need to maintain droplet precautions to avoid the spreading of an infectious disease. The intent of this model is to provide insight to the problem of aerosol contamination in aircraft cabins. The accuracy of the results using a model cannot be guaranteed in all situations, therefore as time and expense allow experimental verification is required.

\section{Conclusion}

A model of aerosol particles in a closed space with air flow provides applied researchers insight as to how various variables play a role in air quality and particle inhalation. Aerosol contaminants in an aircraft passenger cabin may be a concern when there is the possibility of an infectious transmission of a disease. The COVID19 pandemic is an example for further research. Field experiments are invaluable in this quest, but they can be time consuming, costly and sometimes impractical to perform. Incorporating a model can give insight to how the important variables 
International Journal of Aviation, Aeronautics, and Aerospace, Vol. 8 [2021], Iss. 1, Art. 6

affect the air quality and serve to fill in any gaps in knowledge when relying solely on experimentation. 


\section{References}

Paulo, A. C., Correia-Neves, M., Domingos, T., Murta, A. G., \& Pedrosa J. (2010). Influenza infectious dose may explain the high mortality of the second and third wave of 1918-1919 influenza pandemic. PLoS ONE 5(7), e11655. https://doi.org/10.1371/journal.pone.0011655

Schröder, I. (2020). COVID-19: A risk assessment perspective. ACS Chemical Health \& Safety, 27(3), 160-169. doi:10.1021/acs.chas.0c00035

Silcott, D., Silcott, B., Distelhorst, S., Herrera, V., Rivera, D., Crown, K., Lucero, G., Bryden, W., McLoughlin, M., Cetta, M., \& Accardi, R. (2020). TRANSCOM/AMC commercial aircraft cabin aerosol dispersion tests. https://www.ustranscom.mil/cmd/docs/TRANSCOM\%20Report\% 20Final.pdf

Silich, B. A. (2020). Method to reduce aerosolized contaminant concentration exposure to healthcare workers during the COVID-19 pandemic when temporary isolation systems are required. Western Journal of Emergency Medicine: Integrating Emergency Care with Population Health, 21(6), 9398. http://dx.doi.org/10.5811/westjem.2020.9.48170 Retrieved from https://escholarship.org/uc/item/8d1684jn. 


\section{Appendix 1}

\section{Determining Number of Contagious Passengers}

\section{Example calculation using testing (refer to Table 1)}

\begin{tabular}{|c|c|c|c|c|c|c|}
\hline Prevalance & Disease & Test Result & Term & $(\%)$ & $\begin{array}{c}\text { Number out of } \\
100 \text { total }\end{array}$ & $\begin{array}{l}\text { Removed Remain } \\
\text { from Flight on Flight }\end{array}$ \\
\hline $5 \%$ & present & positive & True Positive & $70 \%$ & 3.5 & 3 \\
\hline $5 \%$ & present & negative & False Negative & $30 \%$ & 1.5 & 2 \\
\hline $95 \%$ & not present & positive & False Positive & $5 \%$ & 4.8 & 5 \\
\hline \multirow[t]{2}{*}{$95 \%$} & not present & negative & True Negative & $95 \%$ & 90.3 & 90 \\
\hline & & & & & 100.0 & 92 \\
\hline
\end{tabular}

1. Assume the prevalence of the disease within the population is $\mathrm{Pp} \%=5 \%$. Therefore, the prevalence without the disease within the population is $\mathrm{Pn} \%$ $=95 \%$.

2. Total number of passengers expecting to board is $n=100$.

3. Assume the false negative percent is $\mathrm{Fn} \%=30 \%$. Therefore, the true positive percent is $\mathrm{Tp} \%=70 \%$.

a. Number of passengers in the group that will test positive and have the disease are the true positives (Tp).

$$
\mathrm{Tp}=\mathrm{n} * \mathrm{Pp} \% * \mathrm{Tp} \%=3.5
$$

b. Number of passengers in the group that will test negative and have the disease are the false negatives (Fn).

$$
\mathrm{Fn}=\mathrm{n} * \mathrm{Pp} \% * \mathrm{Fn} \%=1.5
$$

4. Assume the false positive percent is $\mathrm{Fp} \%=5 \%$. Therefore, the true negative percent is $\operatorname{Tn} \%=95 \%$.

a. Number of passengers in the group that will test positive without having the disease are false positives (Fp).

$$
\mathrm{Fp}=\mathrm{n} * \mathrm{Pn} \% * \mathrm{Fp} \%=4.8
$$

b. Number of passengers in the group that will test negative without having the disease are true negatives (Tn).

$$
\mathrm{Tn}=\mathrm{n} * \operatorname{Pn} \% * \operatorname{Tn} \%=90.3
$$


At this point, if testing is accomplished prior to the flight, the true positives (rounded to 3) and the false positives (rounded to 5) will need to be removed from the flight. $5 \%$ of the healthy passengers are inconvenienced by being removed. The false negative passengers (rounded to 2) will still get on board with the disease. Of the 92 passengers allowed to board, $1.6 \%$ of them should be considered contagious.

\section{Example calculation using clinical screening (refer to Table 2)}

\begin{tabular}{cccccccc} 
& \multicolumn{9}{c}{ Table 2 - Passenger flight screening using clinical screening } \\
Prevalance & Disease & Clinical Screen & Term & (\%) & $\begin{array}{c}\text { Number out of } \\
\text { 100 total }\end{array}$ & $\begin{array}{c}\text { Removed } \\
\text { from Flight on Flight }\end{array}$ \\
\hline $5 \%$ & present & symptomatic True Positive & $20 \%$ & 1.0 & 1 & \\
$5 \%$ & present & asymptomatic False Negative & $80 \%$ & 4.0 & & 4 \\
$95 \%$ & not present symptomatic False Positive & $3 \%$ & 2.9 & 3 & \\
$95 \%$ & not present asymptomatic True Negative & $97 \%$ & 92.2 & & 92 \\
\hline
\end{tabular}

1. Assume the prevalence of the disease within the population is $\mathrm{Pp} \%=5 \%$. Therefore, the prevalence without the disease within the population is $\mathrm{Pn} \%$ $=95 \%$.

2. Total number of passengers expecting to board is $n=100$.

3. Assume the population with the disease that are symptomatic have a true positive percent or $\mathrm{Tp} \%=20 \%$. Therefore, the population with the disease that are asymptomatic have a false negative percent or Fn $\%=80 \%$.

a. Number of passengers in the group screened as symptomatic and have the disease are the true positives (Tp).

$$
\mathrm{Tp}=\mathrm{n} * \mathrm{Pp} \% * \mathrm{Tp} \%=1.0
$$

b. The number of passengers in the group screened as asymptomatic and with the disease are the false negatives (Fn).

$$
\mathrm{Fn}=\mathrm{n} * \mathrm{Pp} \% * \mathrm{Fn} \%=4.0
$$

4. Assume the population without the disease but have some form of symptoms have a false positive percent or $\mathrm{Fp} \%=3 \%$. Therefore, the population without the disease and no suspicious symptoms have a true negative percent or $\operatorname{Tn} \%=97 \%$.

a. Number of passengers in the group screened as symptomatic without having the disease are false positives (Fp).

$$
\mathrm{Fp}=\mathrm{n} * \mathrm{Pn} \% * \mathrm{Fp} \%=2.9
$$


International Journal of Aviation, Aeronautics, and Aerospace, Vol. 8 [2021], Iss. 1, Art. 6

b. Number of passengers in the group screened as asymptomatic without having the disease are true negatives (Tn).

$$
\mathrm{Tn}=\mathrm{n} * \mathrm{Pn} \% * \operatorname{Tn} \%=92.2
$$

At this point, if only screening is accomplished prior to the flight, the true positives (1) and the false positives (rounded to 3) will need to be removed from the flight. $3 \%$ of the healthy passengers are inconvenienced by being removed. The false negative passengers (4) will still get on board with the disease. Of the 96 passengers allowed to board, $4.2 \%$ of them should be considered contagious. 


\section{Appendix 2}

\section{Contamination of an Isolated Volume, General Solution}

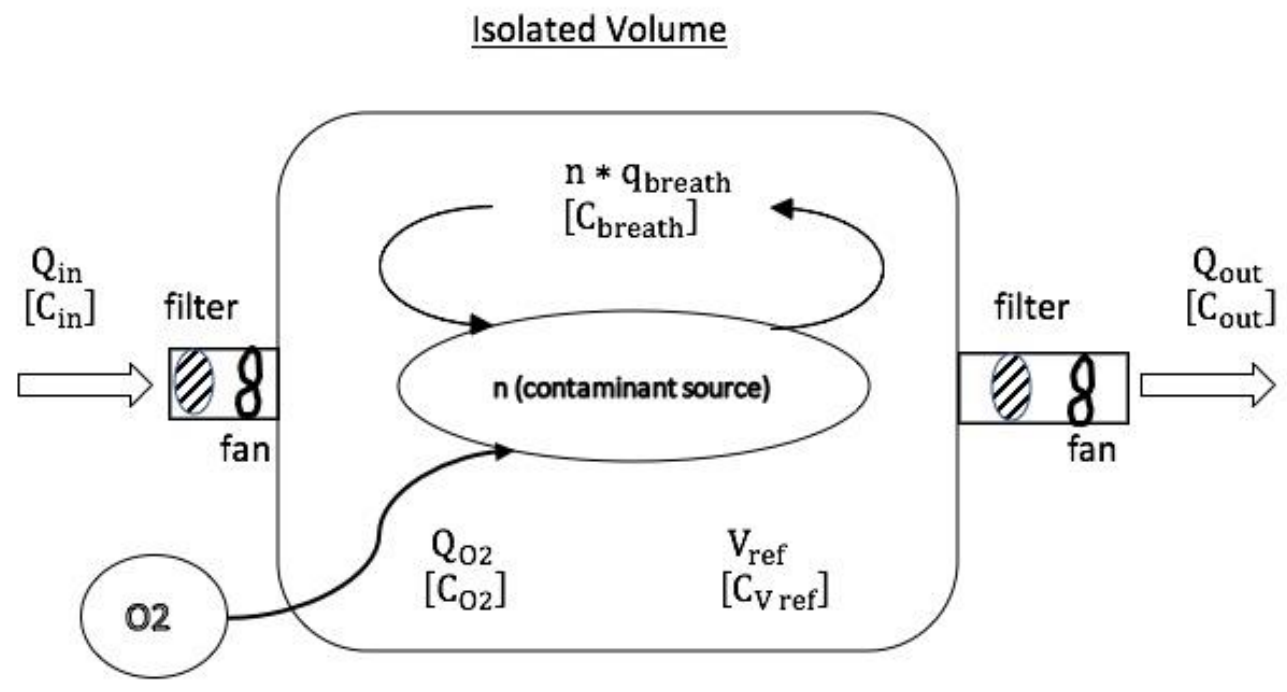

Figure 1

\section{Definitions}

$\mathrm{ACH}$ - Air Changes / hour

[C] - Concentration (particles $/ \mathrm{m}^{\wedge} 3$ )

CCR - Contaminant Concentration Ratio

O2 - Oxygen supply

$\mathrm{n}$ - number of identical contaminant sources

$P$ - \# Contaminant particles

$\mathrm{Q}, \mathrm{q}$ - Flow rate ( $\mathrm{m}^{\wedge} 3 /$ hour)

RR - Respiratory rate (1/hour)

$\mathrm{t}$ - time (hours)

TV - Tidal volume $\left(\mathrm{m}^{\wedge} 3\right)$

$\mathrm{V}_{\text {ref }}$ - Reference volume $\left(\mathrm{m}^{\wedge} 3\right)$

Virion - a complete virus particle
Important Relationships

$[\mathrm{C}]=\frac{\mathrm{P}}{\mathrm{V}} \quad\left(\right.$ particles $\left./ \mathrm{m}^{\wedge} 3\right)$

$\left[\mathrm{C}_{\text {out }}\right]=\left[\mathrm{C}_{\mathrm{V} \text { ref }}\right]$

$\mathrm{q}_{\text {breath }}=(\mathrm{TV} * \mathrm{RR})$

$\mathrm{Q}_{\text {out }}=\mathrm{Q}_{\text {in }}+\mathrm{Q}_{\mathrm{O} 2}$

$\mathrm{Q}_{\text {out }}=\mathrm{ACH} * \mathrm{~V}_{\text {ref }}$

Flow rate of contaminant

$\frac{\mathrm{dP}}{\mathrm{dt}}=\dot{\mathrm{P}}=\mathrm{Q} *[\mathrm{C}]$

(particles/hour)

1 particle $=1$ virion 


\section{Solution}

Assume perfect mixing of an aerosolized contaminant and all aerosolized particles of any size are equally affect by the air flow.

$$
\dot{\mathrm{P}}_{\mathrm{V} \text { ref }}=\dot{\mathrm{P}}_{\mathrm{breath}}+\dot{\mathrm{P}}_{\mathrm{O} 2}+\dot{\mathrm{P}}_{\text {in }}^{\prime}-\dot{\mathrm{P}}_{\text {out }} \quad \text { (particles/hour) }
$$

Assume there is no contamination from the oxygen source, therefore $\dot{\mathrm{P}}_{\mathrm{O} 2}=0$.

$$
\begin{aligned}
& \dot{\mathrm{P}}_{\mathrm{V} \text { ref }}+\dot{\mathrm{P}}_{\text {out }}=\dot{\mathrm{P}}_{\text {breath }}+\dot{\mathrm{P}}_{\text {in }}^{\prime} \\
& \dot{\mathrm{P}}_{\mathrm{V} \text { ref }}+\mathrm{Q}_{\text {out }} *\left[\mathrm{C}_{\text {out }}\right]=\mathrm{n} * \mathrm{q}_{\text {breath }} *\left[\mathrm{C}_{\text {breath }}\right]+\dot{\mathrm{P}}^{\prime}{ }_{\text {in }} \\
& \dot{\mathrm{P}}_{\mathrm{V} \text { ref }}+\left(\frac{\mathrm{Q}_{\text {out }}}{\mathrm{V}_{\text {ref }}}\right) * \mathrm{P}_{\mathrm{V} \text { ref }}=\mathrm{n} * \mathrm{q}_{\text {breath }} *\left[\mathrm{C}_{\text {breath }}\right]+\dot{\mathrm{P}}_{\text {in }}^{\prime}
\end{aligned}
$$

The $\dot{\mathrm{P}}^{\prime}{ }_{\text {in }}$ term may include HEPA filtered recycled air from the reference volume with a flow rate such that $\mathrm{Q}_{\mathrm{in}}=\mathrm{k} * \mathrm{Q}_{\text {out }}$ with $0 \leq \mathrm{k} \leq 1$. Its concentration will then be $(1-\mathrm{HEPA}) *\left[\mathrm{C}_{\text {out }}\right]$. Other unspecified input sources of particles, $\dot{\mathrm{P}}_{\mathrm{in}}$, may also be present. Therefore, we can write this expression as

$$
\dot{\mathrm{P}}^{\prime}{ }_{\text {in }}=(1-\mathrm{HEPA}) * \mathrm{k} * \mathrm{Q}_{\text {out }} *\left[\mathrm{C}_{\text {out }}\right]+\dot{\mathrm{P}}_{\text {in }}
$$

Simplify by substitution where,

$$
\begin{aligned}
& \mathrm{ACH}=\left(\frac{\mathrm{Q}_{\text {out }}}{\mathrm{V}_{\text {ref }}}\right) \\
& \alpha=\mathrm{n} * \mathrm{q}_{\text {breath }} *\left[\mathrm{C}_{\text {breath }}\right]+\dot{\mathrm{P}}_{\text {in }} \\
& \beta=(1-\mathrm{k}(1-\mathrm{HEPA})) \neq 0 \\
& \mathrm{k}=\frac{\mathrm{Q}_{\text {in }}}{\mathrm{Q}_{\text {out }}}
\end{aligned}
$$




$$
\mathrm{HEPA}=\frac{\mathrm{HEPA} \%}{100}
$$

are constants. The equation is now written as

$$
\dot{\mathrm{P}}_{\mathrm{V} \text { ref }}+\beta * \mathrm{ACH} * \mathrm{P}_{\mathrm{V} \text { ref }}=\alpha
$$

The general solution to this $1^{\text {st }}$ order, linear, ordinary differential equation is the sum of its particular and homogeneous solutions.

$$
\mathrm{P}(\mathrm{t})_{\mathrm{V} \text { ref }}=\left(\frac{\alpha}{\beta * \mathrm{ACH}}\right)+\text { Constant }_{\mathrm{H}} * \mathrm{e}^{-\beta * \mathrm{ACH} * \mathrm{t}}
$$

The number of particles at time $=0$ is $\mathrm{P}(0)_{\mathrm{V} \text { ref }}$.

$$
\text { Constant }_{\mathrm{H}}=\left\{\mathrm{P}(0)_{\mathrm{V} \text { ref }}-\left(\frac{\alpha}{\beta * \mathrm{ACH}}\right)\right\}
$$

The solution reveals the number of contaminant particles in the reference volume as a function of time.

$$
\mathrm{P}(\mathrm{t})_{\mathrm{V} \text { ref }}=\left(\frac{\alpha}{\beta * \mathrm{ACH}}\right)+\left\{\mathrm{P}(0)_{\mathrm{V} \text { ref }}-\left(\frac{\alpha}{\beta * \mathrm{ACH}}\right)\right\} * \mathrm{e}^{-\beta * \mathrm{ACH} * \mathrm{t}}
$$

Concentration is determined by dividing by $\mathrm{V}_{\text {ref }}$.

$$
\left[\mathrm{C}(\mathrm{t})_{\mathrm{V} \text { ref }}\right]=\left(\frac{\alpha}{\beta * \mathrm{Q}_{\text {out }}}\right)+\left\{\left[\mathrm{C}(0)_{\mathrm{V} \text { ref }}\right]-\left(\frac{\alpha}{\beta * \mathrm{Q}_{\text {out }}}\right)\right\} * \mathrm{e}^{-\beta * \mathrm{ACH} * \mathrm{t}}
$$

This solution can also be written as the ratio of contaminant concentration in the reference volume compared to the contaminant concentration of the source. 


$$
\begin{gathered}
\operatorname{CCR}(\mathrm{t})=\frac{\left[\mathrm{C}(\mathrm{t})_{\mathrm{V} \mathrm{ref}}\right]}{\left[\mathrm{C}_{\text {breath }}\right]}=\left(\frac{\alpha}{\left[\mathrm{C}_{\text {breath }}\right] * \beta * \mathrm{Q}_{\text {out }}}\right)+ \\
\left\{\left[\operatorname{CCR}(0)_{\mathrm{V} \text { ref }}\right]-\left(\frac{\alpha}{\left[\mathrm{C}_{\text {breath }}\right] * \beta * \mathrm{Q}_{\text {out }}}\right)\right\} * \mathrm{e}^{-\beta * \mathrm{ACH} * \mathrm{t}}
\end{gathered}
$$

The steady state value is the constant at time $=\infty$.

$$
\begin{array}{r}
\operatorname{CCR}(\infty)=\frac{\left[\mathrm{C}(\infty)_{\mathrm{V} \text { ref }}\right]}{\left[\mathrm{C}_{\text {breath }}\right]}=\left(\frac{\alpha}{\left[\mathrm{C}_{\text {breath }}\right] * \beta * \mathrm{Q}_{\text {out }}}\right) \\
=\left(\frac{\mathrm{n} * \mathrm{q}_{\text {breath }} *\left[\mathrm{C}_{\text {breath }}\right]+\dot{\mathrm{P}}_{\text {in }}}{\left[\mathrm{C}_{\text {breath }}\right] * \beta * \mathrm{Q}_{\text {out }}}\right)
\end{array}
$$

Time for $\mathrm{xy} \%$ of the exponential decay, $\mathrm{T}_{\mathrm{xy} \%}$, to occur means the magnitude of the exponential component, $\mathrm{e}^{-\beta * \mathrm{ACH} * \mathrm{~T}_{\mathrm{xy}} \%}$, is equal to $(1-0 . \mathrm{xy})$. For $\mathrm{t} \geq 0, \mathrm{e}^{-\beta * A C H * t}$ determines the decay as its magnitude progresses from 1 to 0 as time goes to infinity.

$$
\begin{aligned}
& e^{-\beta * A C H * T_{x y} \%}=(1-0 . x y) \\
& \ln \left(e^{\left.-\beta * A C H * T_{x y}\right)}=\ln (1-0 . x y)\right. \\
& T_{x y \%}=-\frac{\ln (1-0 . x y)}{\beta * A C H}
\end{aligned}
$$

The number of aerosol particles inhaled by a healthy individual, $\mathrm{P}_{\mathrm{inh}}$, can be calculated. Multiplying the breathing rate, $\mathrm{q}_{\text {inh }}\left(\mathrm{m}^{\wedge} 3 /\right.$ hour$)$, by the concentration of the of the contaminant, $\left[\mathrm{C}(\mathrm{t})_{\mathrm{V} \text { ref }}\right]$ (particles $/ \mathrm{m}^{\wedge} 3$ ), and time (hours). Since $\left[\mathrm{C}(\mathrm{t})_{\mathrm{V} \text { ref }}\right]$ varies with time, integration is required.

$$
\begin{gathered}
\mathrm{P}_{\mathrm{inh}}=\int_{t 1}^{t 2} \mathrm{q}_{\mathrm{inh}} *\left[\mathrm{C}(\mathrm{t})_{\mathrm{V} \mathrm{ref}}\right] * \mathrm{dt} \\
\mathrm{P}_{\mathrm{inh}}=\mathrm{q}_{\mathrm{inh}} * \int_{t 1}^{t 2}\left(\left(\frac{\alpha}{\beta * \mathrm{Q}_{\text {out }}}\right)+\left\{\left[\mathrm{C}(0)_{\mathrm{V} \mathrm{ref}}\right]-\left(\frac{\alpha}{\beta * \mathrm{Q}_{\text {out }}}\right)\right\} * \mathrm{e}^{-\beta * \mathrm{ACH} * \mathrm{t}}\right) * d t
\end{gathered}
$$




$$
\mathrm{P}_{\text {inh }}=\left.\mathrm{q}_{\text {inh }} *\left(\left(\frac{\alpha}{\beta * \mathrm{Q}_{\text {out }}}\right) * t+\frac{\left\{\left[\mathrm{C}(0)_{\mathrm{V} \mathrm{ref}}\right]-\left(\frac{\alpha}{\beta * \mathrm{Q}_{\text {out }}}\right)\right\}}{-\beta * \mathrm{ACH}} * \mathrm{e}^{-\beta * \mathrm{ACH} * \mathrm{t}}\right)\right|_{\mathrm{t} 1} ^{\mathrm{t} 2}
$$

The value for $\mathrm{n}$ contained in $\alpha$ would be 1 since the calculation is for a single individual.

It is important to emphasize that these equations are valid only if all the terms except $t$ remain constant. If additional sources are required, they can be represented by $\dot{\mathrm{P}}_{\mathrm{in}}$. If $\dot{\mathrm{P}}_{\text {in }}$ is not constant, a numerical methods approach would be required to obtain the solution. 